\title{
The effects of different irrigation frequencies and levels of water quality on maize yield and growth Irrigatuin frequency and water quality impacts on maize crop
}

\author{
M. T. Amin", A. A. Alazba, M. Rizwan
}

\section{Abstract - The effects of different irrigation frequencies and} levels of water quality on maize yield and growth parameters under raised bed and drip irrigation systems were examined. Three irrigation frequencies (every 2,4 or 6 days) and three levels of irrigation water quality (good, marginal and poor) were applied using the high-efficiency drip irrigation system and raised bed systems. The parameters measured were germination rate, plant height, total dry matter (TDM), and grain yield (GY). The data were statistically investigated to assess the importance of irrigation frequency and water quality. The effects of irrigation frequency on plant height were observed to be statistically significant. Plant height reduced with an increase in irrigation frequency from every 2 to every 4 days, but increased with a further increase in irrigation frequency from every 4 to every 6 days. The raised bed irrigation system demonstrated better performance than the drip irrigation system; plant height, biological yield and maize yield in the former system were $1 \%$, $5 \%$ and $21 \%$ higher, respectively, than in the latter. The main effect of irrigation frequency on the TDM weight was statistically significant, suggesting that the irrigation frequency had a clearcut effect on TDM weight. The vigorous crop growth in those plots irrigated using the raised bed irrigation system is likely to be due to salts being removed from the crop root zone through leaching. Despite this, the raised bed irrigation system is not preferred over drip irrigation as it uses more irrigation water in crop production.

Keywords - Irrigation frequency and system, maize crop, water quality

M. T. Amin (*Corresponding Author)

Alamoudi Water Research Chair, King Saud University,

Riyadh 11451, Kingdom of Saudi Arabia

A. A. Alazba

Alamoudi Water Research Chair, King Saud University, Riyadh 11451, Kingdom of Saudi Arabia

M. Rizwan

Department of Civil and Environmental Engineering, Hanyang University, Seoul, South Korea 